\title{
Police Legitimacy
}

Police legitimacy-that is, public trust in and a felt obligation to obey the police-forms the fulcrum of the procedural justice model of policing. Such outlooks are intrinsically important, of course, and they are important also because research suggests that they lead to other valued outcomes: compliance with the law, providing information to police, working with them on community problems, and accepting police directions and decisions in police-citizen encounters. Tom Tyler's model of process-based regulation (Tyler 1988, 1990, 2003, 2004; Tyler, Goff, and MacCoun, 2015) holds that trust is influenced by the procedural justice with which authorities are perceived to wield their powers, and so it would appear to be susceptible to enhancement through improvements in the procedural justice with which police act.

In this chapter, we explain our use of terms and concepts, lest we confuse the meaning of legitimacy as a construct of institutional theory with that of the constructs in social psychological theory. We first consider trust and obligation in the context of public attitudes toward the police more generally, including their historical trends and the forces that influence those attitudes. Public attitudes toward the police are subject to some broad social factors that have shaped attitudes toward government and other social institutions, as well as factors more peculiar to policing. We discuss those here so that we can better understand the role that citizens' own experiences with the police play in contributing to (or detracting from) their trust and confidence in police. Citizens' direct contacts with the police are not the only influence on trust; moreover, citizens' interpretations of their contacts with the police are themselves subject to the influence of prior attitudes and contextual factors. We also assess citizens' satisfaction with the police as a special case 
of "customer" satisfaction. We consider the respects in which citizens resemble customers, and those in which the analogy to customers breaks down, and briefly discuss selected findings from research on customer satisfaction that may serve to place citizens' satisfaction with the police in perspective. Then we consider how levels of public trust may be related to the legitimacy of police departments, as an organizational property, and discuss challenges to police legitimacy in the form of diminished trust and also, more overtly, protests and riots.

We then present survey results that bear on public trust and obligation in Schenectady and Syracuse, which serves two purposes. First, an analysis of the levels of public trust of the study departments enables us to consider them in the larger context of their public images. Second, by establishing the measurement properties of the trust and obligation constructs that can be derived from the survey data, we will be better able in the next chapter to determine the extent to which the subjective experiences of people in Schenectady and Syracuse exhibit the same kinds of associations with trust and obligation as those commonly reported in previous research.

\section{PUBLIC TRUST AND OBLIGATION}

From the perspective of social psychology, at least two strands of legitimacy have been identified; we will call them trust and obligation. With respect to the police in particular, the Committee to Review Research of the National Research Council $(2004,291)$ explained that by "legitimacy we mean the judgments that ordinary citizens make about the rightfulness of police conduct and the organizations that employ and supervise them." However, Tyler has emphasized the obligation to obey an authority as a hallmark of its legitimacy. For his seminal study of Chicago, Tyler conceived legitimacy as not only "support for legal authorities" but also a "perceived obligation to obey," and the latter aspect-obligation-is prominently featured: "When people feel that an authority is legitimate, they authorize that authority to determine what their behavior will be within a given set of situations" (Tyler 2004, 87).

However, empirical research that has examined the dimensionality of these legitimacy constructs has shown that indicators of trust in or support for police are manifestations of a latent construct that is distinct from that of obligation. In an analysis of the construct validity of process-based measures, Reisig, Bratton, and Gertz 2007 concluded that trust and obligation are distinct constructs only moderately related to one another. Similarly, Jacinta Gau (2011) found a two-dimensional structure underlying these indicators. Moreover, Reisig et al. (2007, 1022-23) found that trust affected both cooperation and compliance, while obligation affected neither cooperation nor compliance. Hence, we treat trust and obligation as two distinct social psychological dimensions. 
Tyler's model of process-based regulation is the predominant social psychological theory of legitimacy. In this model, procedural justice is the central antecedent of legitimacy: "legitimacy develops from and is maintained by the fair exercise of authority on the part of the police when they deal with the public-that is, through the provision of procedural justice" (Tyler, Goff, and MacCoun 2015; also see Tyler 1988, 1990, 2003, 2004; Tyler and Fagan 2008; Tyler and Huo 2002). Procedural justice is not about whether but rather how authority is exercised. As Schulhofer, Tyler, and Huq 2011 indicates, police need not choose between being tough and being fair; they can be both tough and fair.

Although Tyler's model has been the conceptual touchstone for social psychological research on police legitimacy, it would be an exaggeration to say that a consensus has emerged on the definition of legitimacy. Justice Tankebe (2013; 2014) insists that legitimacy should not be conflated with either trust or obligation; police legitimacy, he argues, has four dimensions: lawfulness; procedural fairness; distributive fairness; and effectiveness. James Hawdon (2008) maintains that legitimacy is different from trust. And Ben Bradford and Jonathan Jackson (2009) note that though there may be important differences among trust, confidence, support, satisfaction, and legitimacy, much of the research on public attitudes toward the police is predicated on an assumption that people tend to subscribe to a single outlook about the police that shapes their judgments about various aspects of the police. We acknowledge these cautions without accepting their implications. In view of these competing views of legitimacy, and the potential for confusing it with organizational legitimacy, we focus as appropriate on trust and obligation.

\section{Public Trust of Police in Context}

Our understanding of trust and confidence in the police is enriched by placing it in the larger context of facts about public attitudes. First, the public's trust in "government," which has been tracked for many years in the American National Election Studies (ANES), declined from 76 percent in 1964 to 25 percent in 1980, and since then has exceeded 50 percent only once, in 2002. ${ }^{1}$ The ANES trust in government index, which combines responses to four survey items that all concern the federal government, fell from its peak of 61 in 1966 to 27 in 1980, and through 2008 never again reached 50, fluctuating mainly in the 20 and 30 s. $^{2}$ This decline in trust in the government to some extent paralleled a broader decline in trust and confidence in social institutions, such as the press, medicine, and education (Smith 2008).

Second, in general, the public now has more confidence in state and local governments (Gerstenson and Plane 2007; Orren 1997), and more confidence in some institutions than it has in others. In June 2014, 53 percent of the respondents to a Gallup poll had a "great deal" or "quite a lot" of confidence in the police, which was a level of confidence lower than that of only the military and small business. Other institutions did not stack up so well in the public's eyes. Only 34 percent expressed 
a comparable level of confidence in medicine, 26 percent in public schools, 23 percent in the criminal justice system, and less than 10 percent in Congress. Between 1993 and 2014, confidence in the police fluctuated between 52 and 64 percent. Over the same time period, confidence in the public schools dropped from 39 percent to 32, while confidence in the Supreme Court dropped from 44 percent to 34 (with an intervening rise to 50 percent between 1997 and 2002). Confidence in the criminal justice system improved over that same span, from 17 percent in 1993 to 23, peaking at 34 percent in 2004, but it was uniformly lower than that in the police. ${ }^{3}$

Even in the immediate aftermath of the series of deadly force incidents in 2014-15, a Gallup poll in June 2015 found that 52 percent of Americans had a "great deal" or "quite a lot" of confidence in the police (Jones 2015), and though that figure was the lowest since 1993, the police still enjoyed more of the public's trust and confidence than all but two of the social institutions about which Gallup inquires. Public ratings of the honesty and ethics of police likewise dropped in 2014, but by the end of 2015 they had rebounded (Saad 2015). We have previously seen such dips in confidence following high-profile incidents, with rebounds thereafter (Weitzer 2002).

Analyses of the decline in trust in government have identified several sources. Gary Orren (1997) notes the backdrop of "traditional skepticism" of governmental power among Americans, and the long-term trend in the United States and elsewhere in the first world toward "post-material values" that foster "authoritychallenging attitudes," such as self-expression and self-realization. Shorter-term changes in trust stem from: assessments of government performance against public expectations; disagreement with the direction of government policy; negative assessments of the honesty and integrity of public officials; and denunciations of government by public officials and the media. Trust and confidence in police has not declined so much as that in government generally, but it has not improved as much as police performance and fairness has arguably improved, which Lawrence W. Sherman (2002) attributes to broad cultural shifts in public expectations. We might suppose that trust and confidence in the police would turn especially on the perceived integrity of the police, and not very much on (actual) performance, since the public's perceptions of and concern about crime are not closely linked to actual crime levels.

Much of the research on the public's attitudes toward the police has addressed, not trust or confidence as such, but rather "satisfaction" with police. The referent in survey items varies - for example, it might be either police services in your neighborhood or the police department in your city-but the satisfaction about which respondents are queried is in many instances not specific to a particular, concrete experience with the police but rather more global and abstract. Even people who have not had (ever or recently) contact with the police typically have an opinion about the police. We suspect that citizens' global satisfaction with their 
local police is strongly associated with their trust and confidence in their local police, and if that is so, we can learn something about trust from previous research on satisfaction with the police.

The racial disparity in Americans' attitudes toward the police has been as durable as it is remarkable. Blacks have less favorable attitudes than whites do, and Hispanics' attitudes also tend to be less positive than those of whites. This gap is nearly uniform in its direction, if not its magnitude, across time and space in the United States (for a rare exception to the more general rule, see Frank et al. 1996). Much of the research on attitudes toward the police has dwelled at least to some degree on the origins, meaning, and implications of this disparity.

It appears that attitudes toward the police are shaped to some degree by the severity or perceived severity of social and physical disorders in urban neighborhoods, for which (we might infer) the public holds the police responsible (Reisig and Parks 2000; Sampson and Bartusch 1998). Thus attitudes are more positive where (and by those whom) such incivilities-for example, vandalism, noise, open-air drug markets, abandoned cars-are perceived to be less serious problems. Variation in these quality-of-life conditions may account for at least some of the racial disparity in attitudes toward the police.

Attitudes toward the police also correlate with citizens' subjective experiences with the police in individual contacts, both voluntary contacts-when citizens report crimes or request assistance-and involuntary contacts-when they are stopped by the police. The correlation reflects reciprocal causal effects: satisfaction with the individual contact affects more global satisfaction with the police, but more global attitudes toward the police also shape the perceived quality of police performance in individual police-citizen encounters (Brandl et al. 1994; Rosenbaum et al. 2005; Tyler 1987, 1990). Most of the research that reports on this correlation is cross-sectional, and so it is unable to tease the reciprocal effects apart; multiwave panel surveys are necessary, providing for interviewing the same respondents at two (or more) points in time. Global satisfaction-satisfaction with the police overall-is measured at both times, and in a second survey wave, subjective experience is assessed retrospectively, such that the effects of prior (firstwave, or $\mathrm{T}_{1}$ ) attitudes on subjective experience can be estimated, and the effects of subjective experience on later (second-wave, or $\mathrm{T}_{2}$ ) attitudes can be separately estimated, controlling for the effects of $\mathrm{T}_{1}$ attitudes on $\mathrm{T}_{2}$ attitudes. See figure 1 .

Such panel studies find that a substantial fraction of the association between the perceived quality of citizens' experiences with the police and their more general attitudes toward the police reflect the effect of the latter on the former: citizens' subjective experiences are shaped by their prior attitudes much more than their experiences shape their subsequent attitudes. Global attitudes tend to be stable, and any one contact has a limited effect on citizens' broader views of police. But global attitudes have strong effects on citizens' interpretations of their experiences. 
Wave 1 survey Wave 2 Survey

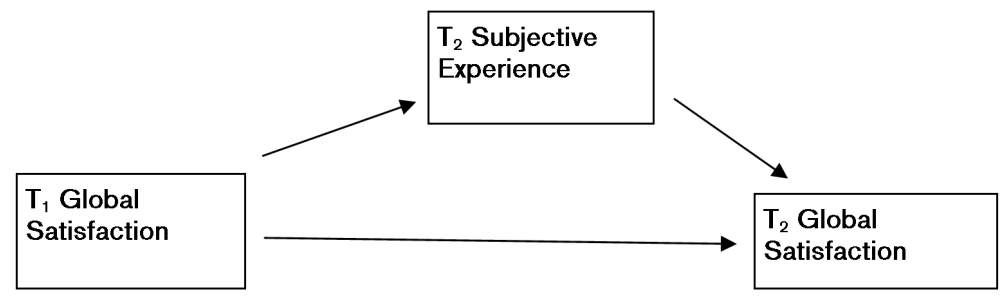

FIGURE 1. Panel Survey Logic.

The effects of global attitudes on subjective experience may be greater for blacks than for whites. Jon Hurwitz and Mark Peffley (2005) surveyed samples of blacks and whites about their beliefs about the fairness of the justice system, and also elicited respondents' judgments about the propriety of police enforcement actions in each of two scenarios in which the race of the citizen was experimentally manipulated. They found considerable support for their "perceived discrimination hypothesis":

Given the history of racial bias in the system, African Americans should be more vigilant to signs of discrimination in encounters between police and black civilians. Brutality and profiling are so familiar to many African Americans that they constitute chronically accessible "scripts" that are frequently primed and likely to guide interpretations of ambiguous events. . . Thus, blacks as a group are likely to view confrontations between police and black civilians as yet another instance of police discrimination. (Hurwitz and Peffley 2005, 767)

The effects of global attitudes on citizens' interpretations of the scenarios were greater among blacks than among whites.

One recent study (Braga et al. 2014), which also employed experimentally manipulated scenarios, further suggests that citizens' assessments of police conduct are affected by broader matters of context, such as the climate of police-community relations: whether "the police department had been cited for its strong community policing work, had received extensive negative media coverage for poor community relations and civil rights violations."

Moreover, the effects of subjective experiences on more global attitudes toward the police are asymmetrical: unfavorable experiences have a more detrimental effect on attitudes toward the police than favorable experiences have a beneficial effect. Skogan (2006) goes so far as to assert that police are in a no-win situation, finding that positive experiences do not move the attitudinal needle, whereas 
negative experiences detract from global satisfaction. He locates this asymmetry in a broader set of findings in psychological research that reveals

a strong "negativity bias" that shapes the interpretation that people give to their dayto-day experiences. ... The lessons of bad things are learned more quickly, and forgotten more slowly, than the lessons of positive experiences. When people are faced with a mix of positive and negative experiences, the negative ones predominate in shaping both attitudes and behavior. They pay more careful attention to negative experiences, and think about them and recall them later in more elaborate and finegrained fashion. (Skogan 2006, 106)

These relationships may also help to account for the disparities in the attitudes of whites and blacks.

Skogan's findings about the effects of subjectively positive experiences with the police are as dispiriting as they are consistent with the psychological research to which he alludes, though one need not conclude that positive experience has no effect on more global attitudes toward the police in order to see merit in the proposition about negativity bias. The panel studies cited above found that positive experience has a beneficial effect of modest magnitude and negative experience has a detrimental effect of greater magnitude. These results have been consistent, though they do not demonstrate that the estimated effects of subjective experience are rooted in the overt actions of police.

However, all of these findings are difficult to reconcile with the fairly high levels of satisfaction with and trust in the police. Given the asymmetrical effects of experience, and given that about one-fifth of the American adult population has a contact each year with the police (mostly through traffic stops), we might deduce that satisfaction and trust would spiral down over time with the predominantly negative effects of experience. Yet that is not what we have seen over time. Clearly, other forces are at work in shaping attitudes toward the police, forces of a longitudinal nature that previous research has missed. Perhaps the effects of experience decay over time.

Research on the etiology of attitudes toward the police is thin. We can safely assume that the typical adult is not a blank slate on which direct experiences with legal actors leave their mark, but to say that prior attitudes influence an individual's judgments about direct experiences is to beg the question: whence do prior attitudes come? We would do well to consider the "primacy principle" of political socialization (Searing et al. 1976), comprised of three assumptions: that political orientations are learned in childhood; that childhood learning shapes later modifications of political attitudes; and that the scale of any such modifications tends to be small. Insofar as the police are one of the most visible manifestations of government, we should take seriously the idea that attitudes toward the police are shaped in important ways through childhood socialization. ${ }^{4}$ Parents and other adult 
guardians would presumably play a large role in childhood legal socialization, as they do in political socialization more generally (see, e.g., Jennings and Niemi 1968, 1975; Jennings, Stoker, and Bowers 2009). Parents can overtly influence their children's outlooks through direct communication that establishes and reinforces ways of interpreting and understanding the world, and they can unobtrusively model beliefs and attitudes for their children. But studies of the influence of parents in legal socialization are few in number, and those that exist appeared only recently.

Amie Schuck (2013) found that youths in 5th or 6th grade (i.e., aged 11 or 12) hold positive attitudes toward the police, though even at this early age, the attitudes of African American youths are less positive than those of white or Latino youths. Further, she found that youths' attitudes tend to become more negative from age 12 until the age of 17 , and that the downward trend holds regardless of adolescents' race, sex, or socioeconomic status; as Schuck observes, "this pattern strongly resembles the archetype theorized for adolescents' perceptions of figures of authority, including parents and teachers, as well as, the pattern described by Fagan and Tyler ... for adolescents' perceptions of legitimacy of the law and legal authorities" $(2013,597)$. Jeffrey Fagan and Tom Tyler argue that "there is a developmental process of legal socialization, and that this process unfolds during childhood and adolescence as part of a vector of developmental capital that promotes compliance with the law and cooperation with legal actors." Summarizing early studies of childhood legal socialization, they observe that "early orientations toward law and government were found to be affective in nature, and characterized by idealized and overly benevolent views about authority. These early views shaped the later views of adolescents, views that were both more cognitive and less idealized in form. In other words, each stage of the socialization process influenced later, more complex, views" (Fagan and Tyler 2005, 218).

The findings of two recent studies testify to the influence of parents on their children's outlooks. Analyzing the attitudes of nearly 1,000 adjudicated delinquents aged 14 to 17 , for each of whom "collateral" interviews were also conducted with a parent, and controlling for a wide range of potentially confounding influences, Wolfe, McLean, and Pratt 2016 found that "parental attitudes regarding the legitimacy of legal authorities influence those same attitudes in their children." Analyzing the attitudes of 315 first-time juvenile offenders aged 13 to 17 and their mothers or female guardians, Cavanagh and Cauffman 2015 similarly found that the mothers' attitudes toward the justice system influenced their sons'. That both studies detected such effects in samples of youth restricted to adjudicated delinquents, all of whom had passed the point at which Schuck found youths' attitudes becoming more negative, suggests that their estimates of parental effects are probably quite conservative.

In a third study, a survey of gth grade students in schools in Queensland, Australia, in which respondents completed items about their attitudes toward the 
police and one on their parents' attitudes toward the police, Elise Sargeant and Christine Bond found that even controlling for police-initiated contacts, prior delinquency, and peer delinquency, perceived parental attitudes are associated with youths' attitudes. (Sargeant and Bond 2015). They point out that "theory suggests that attitudes attributed to others may be more important than actual attitudes," and conclude (albeit speculatively) that "if young people learn attitudes to police from their parents, it may be that negative attitudes to police can then lead to negative police contacts."

Parental influence on their children's attitudes toward the police may be exerted through other mechanisms of childhood and adolescent socialization. Research has shown that parents' monitoring and discipline shapes their children's level of self-control (e.g., Hay, 1981; Pratt, Turner, and Piquero, 2004). Self-control, in turn, is associated with justice system attitudes (Reisig, Wolfe, and Holtfreter 2011; Nivette, Eisner, Malti, and Ribeaud 2014). Thus parenting has both direct and indirect effects on youth attitudes toward the police. ${ }^{5}$

Most research on the attitudes of juveniles has not controlled for the socializing influences of parents, however, and so it risks overestimating the effects of contacts with the police. Piquero et al. 2005 analyzed youthful offenders' trajectories of legitimacy and legal cynicism over an eighteen-month period. The trajectories proved to be largely stable, but they exhibited different levels, and from associations between the levels of these attitudes and subjects' baseline assessments of the procedural justice of police and courts, Alex Piquero and his colleagues inferred that "situational experiences with criminal justice personnel influence more general attitudes about the law and legal system" (296). But they also acknowledge that the stability in the differences "suggests that inter-individual differences among study participants in their cynicism about the legal system likely were established before their first assessment in this study, perhaps as young as fifteen years of age" (287), and the same could be said about their judgments about legitimacy. Megan Augustyn (2015) examined the same sample over a longer time period, finding a decline in offenders' procedural justice judgments, much as Amie Schuck (2013) did, and also that later judgments were influenced by prior judgments. She also found that, curiously, arrests improved offenders' perceptions of procedural justice, and that the positive effect of an arrest increased as offenders aged. In contrast, Amy Nivette et al. (2014) found that, among a general sample of youth, police contacts increased legal cynicism, controlling for prior cynicism (which accounted for half of the explained variance). They further found that self-reported delinquency in the preceding year was a strong predictor of legal cynicism, which they took to suggest that negative (or cynical) attitudes may serve a neutralization function, justifying juveniles' own delinquency. They opine that "following a negative police contact, we venture that cynicism operates as a cognitive distortion that denies the shameful aspects of sanctioning and instead places blame on the law itself" (287). 
Furthermore, much of the research on juveniles' attitudes, like that on adults' attitudes, is cross-sectional, and so the effects of prior attitudes cannot be estimated or controlled. Fagan and Tyler (2005), for example, estimated the effects of procedural justice-the quality of interactions with police, school disciplinary personnel, and private security-on legitimacy, legal cynicism, and moral disengagement among 215 youths aged 10-16, who were interviewed once each. They controlled for a number of personality and contextual factors, but they could not control for prior attitudes. They must therefore assume that procedural justice affects-but is not affected by-legitimacy, and thus they almost certainly overestimate the effect of procedural justice. Other cross-sectional research, however, has found that the effects of youths' experience are mediated by community ties and delinquent subcultures (Brick et al. 2009; Leiber et al. 1998)

The lessons that we take from the research on youths' attitudes toward the police are that trust in the police and other legal institutions, like political attitudes more generally, are to a large degree formed early in life, and while they are not immutable, early attitudes influence later attitude formation. They shape the experiences to which adolescents and young adults are exposed, and they form the lens through which those experiences are interpreted. Adult attitudes toward the police are not simple functions of the treatment that they receive from the police.

We would also note that much of the previous research on procedural justice and legitimacy concerns abstract characterizations of the procedural justice with which police perform and not judgments about how police acted in specific policecitizen encounters. This research has consistently found that people who believe that police act in procedurally just ways tend also to trust the police, and vice versa. That these more abstract judgments about the procedural justice of policing are related to equally abstract outlooks about trust and confidence in police does not necessarily tell us much about how police actually perform, but they do tell us about how people think about the police.

\section{"Customer Satisfaction" in Policing}

Police administrators sometimes invoke a customer analogy in order to promote a more service-oriented mentality and style of policing. Thinking of the people with whom police interact as customers would presumably lead to a heightened attentiveness to what it is that citizens want from the police and greater appreciation of the importance of interpersonal relations. A more customer-friendly approach by police would entail the very actions that comprise procedural justice: asking for and listening to citizens' accounts of the situations in which police and citizens meet one another; courteous treatment; explaining what police are doing and on what basis. Research suggests that these features of the process are important to the people who interact with police. The customer analogy has limits, however, 
and ambiguities in the boundaries of the analogy allow or invite differing interpretations by officers.

A true customer, in a private market transaction, is someone who chooses to seek out a product or service, finds a provider for that product or service and ascertains the price, and enters into a transaction that involves the exchange of the agreed price for the product or service. The exchange is voluntary on the part of both parties, and the price that the customer is willing to pay for the product or service reflects the minimum value that she attaches to the product or service. Her satisfaction with the product or service will turn on a later judgment about the extent to which it met her expectations of it, relative to the price that she paid for it. Chances are that the benefit of the product or service will be limited to her alone (or her household) and not extend to others who are not party to the transaction.

A citizen who calls police to report a stolen bicycle or a loud party, say, resembles such a customer in some respects. He seeks a service-official recognition and recording of a crime of which he is the victim, or third-party intervention to resolve a situation that he defines as a disturbance. His contact with the police is at his initiative and is largely voluntary; he could instead choose to forego any assistance in recovering the bicycle or making an insurance claim, or to tolerate the disturbance that the party represents to him until it ends without intervention.

This transaction, however, is nonvoluntary insofar as the citizen has no options in a police market; in most instances, he must contact his municipal or town police force if he is to receive police service from any agency. Furthermore, he does not pay a discrete price for the service on the occasion on which it is provided; the community has paid for the service, and so beyond any taxes that he might pay (which he is compelled to pay whether he uses the service or not), the service is free to him.

Indeed, any individual member of the community is a customer who pays for the presence and availability of police even if she never requests assistance from the police with respect to a particular situation. These are collective and not individual services; whatever benefits flow from the police services for which she pays in this way are also enjoyed by other members of the community at the same time, and not limited to her or her household. In addition, the payment for these services is nonvoluntary in a different sense: taxes paid to finance police operations are coerced payments.

Mark Moore (2002) points out that police availability to answer emergency calls might come at the expense of quality service to individuals; the time that an officer devotes to high-quality service to one complainant can compromise her capacity to respond promptly to a more urgent situation. More generally, police cannot give "customers" what they want when it exceeds the resource capacity or legal authority of the police to do so. 
Of course, the police also interact with citizens whose contacts with police are not voluntary; suspected offenders have "obligation encounters" with police (Moore 2002). In what sense is a service delivered to people who are taken into police custody for booking, drivers to whom traffic citations are issued, or pedestrians who are stopped on suspicion for questioning? To what kind or level of service are they entitled, given that they may have crossed a legal and/or moral line? At a minimum they are entitled to a level of service mandated by the Constitution: their rights - to be secure in their persons and property against unreasonable intrusions, to be subject to no more than the amount of force necessary to overcome any resistance that they may offer, and against self-incrimination-set a floor on the level of service to be delivered. We might expect a still higher level of service than that, in the form of respectful treatment, because not only of its intrinsic value but also of its hypothesized instrumental value in achieving compliance, and minimizing injuries (to citizens and officers). But the term "customer" is surely stretched in application to these recipients of police service; "client" might be more appropriate.

Like the recipients of many human services, many of the people who interact with police, including even some of those who request police assistance, do not know or recognize what they need and should want. Some of them are incapable of making informed judgments because they are impaired by mental disability or intoxication. Even if they suffer from neither mental illness nor mind-altering substances, they may be ill-equipped to make assessments of the quality of the service options, though that is true of many consumer choices. The single mother of a rebellious teenager who, at her wits end, calls the police may not know what the police should or can do for her. If we suppose that the customer is always right, then, we will be misled by the customer service analogy.

Thus the customer service analogy breaks down in several respects: the recipients of police services-let us call them, generally, clients-are not voluntary in the sense of having a meaningful range of choice in service providers; some encounters are distinctly involuntary; some clients may be incapable of making informed judgments; and clients may lack essential information in assessing the quality of the services they receive. We might add that, unlike private-sector firms, police do not welcome repeat customers; however, police would welcome public "loyalty" insofar as that means public support and cooperation.

Research on customer satisfaction reinforces these observations and offers some additional perspective on citizen satisfaction with police. First, customers tend to be more satisfied with "products" than they are with services (Fornell et al. 1996). Services are "co-produced" by both the provider and the recipient, allowing the provider less control over the process, and services rely more on the human resources of the provider organization, such that they are less susceptible to standardization (Anderson, Fornell, and Rust 1997; Johnson and Fornell 1991; Nilsson 
et al. 2001). Services are more intangible than products, making it "difficult for customers to understand service quality" (Nilsson et al., 2001, 12). This is all surely equally true for police organizations.

Second, employee management has a direct effect on business results (Nilsson et al. 2001) - organizational effectiveness, the use of resources, profits, and revenue growth-as well as indirect effects, through organizational orientations to both customers and processes. Furthermore, customer loyalty to a service provider tends to be earned through high-quality performance, while customer loyalty to a product tends to be "bought" through product discounting, which is not generally feasible with service provision (Edvardsson et al. 2000). These patterns may not hold equally well in public agencies.

Third, customers' expectations of a product or service shape their evaluations of it (Anderson and Fornell 2000; Fornell et al. 1996; Szymanski and Hernard 2001) when they compare their experience with what they expected. Customers have weak or no expectations of a new product with which customers have no experience, meaning that product performance drives satisfaction, but "as customer experience with the product grows and past performance information becomes available, more product-specific expectations develop" (Johnson and Fornell 1991, 275). Hardly anyone has an interaction with the police-even their first personal contact-without having formed expectations-positive or negative-about the police through the socialization process.

Fourth, and relatedly, customers' opportunity for choice can be expected to influence customer satisfaction, since customers who are dissatisfied with one firm's product will turn to those of other firms: "in a competitive environment, people generally do not continue to purchase products toward which they are ambivalent or hold negative evaluations" (Johnson and Fornell 1991, 278). As noted above, clients' range of choice in receiving police services is very restricted.

Some police officers have misgivings about-or reject-a customer-service orientation in policing, reasoning that the people with whom they interact in their day-to-day work are not customers as such. They might well sense the limits of the customer analogy.

\section{PUBLIC TRUST AND ORGANIZATIONAL LEGITIMACY}

The social psychological dimension of trust (but not obligation) bears a fairly strong resemblance to the legitimacy construct that appears in institutional theory. Even so, the two theories diverge somewhat in their conceptions of legitimacy. For social psychological theory, legitimacy-trust-is a property of individuals and it is continuous or at least ordinal: differences in degree matter, both for the level of support that the organization enjoys and for the likelihood of individual compliance with the police and the law. For institutional theory, legitimacy is by 
and large a dichotomous or perhaps trichotomous variable: organizations that are legitimate survive, those that lose legitimacy cease to exist, and organizations whose legitimacy is challenged or threatened can be expected to take steps to regain legitimacy.

Two very important differences between institutional theory and social psychological theory lie in who makes these judgments, or perhaps more accurately, whose judgments matter for the organization, and the basis on which those judgments rest. In social psychological theory, the relevant judgments are those of "ordinary citizens," who evaluate the fairness with which policing is performed. In institutional theory, the pertinent judgments are made by sovereigns such as legislators, professional bodies, and courts-that is, audiences with some standing to make or influence authoritative decisions that have clear implications for the organization. But institutional theory holds that these judgments are based not on technical performance, which is difficult for any audience to judge, but on the police department's conformity to expectations for structural forms. Social psychological theory attributes far greater significance to judgments about the routine exercise of police authority, that is, the technical performance of the organization.

Notwithstanding the trichotomous character of legitimacy in institutional theory, finer differences of degree can be discerned. First, one strategy for maintaining legitimacy is to "stockpile" goodwill (Suchman 1995), so it would seem that an organization can accumulate more or less legitimacy. Second, legitimacy can be challenged by less powerful constituencies, and so, as W. Richard Scott observes, "legitimate' structures may, at the same time, be contested structures" (2014, 73), arguably resting on a lesser foundation of trust.

For all but social survey purposes, citizens' trust in police is not aggregated by computing means or percentages; it is filtered through the judgments of sovereigns. So an agency might thrive despite suffering the distrust of a significant minority of its population. In the absence of polling, it is difficult to say what level of trust an agency enjoys. Citizens' trust, in this political context, is a weighted mean (perhaps a weighted mode)-weighted by political standing and other resources, and not to achieve sample representativeness of the population. Even so, notwithstanding such political weighting, public trust can drop to a level that stimulates a crisis of legitimacy for an agency. John Crank and Robert Langworthy (1992) write about what happens then: a ceremonial replacement of the chief and perhaps some other symbolic, structural reforms (reforms, we would add, that are likely to be only loosely if at all coupled to street policing). The Baltimore Police Department in the wake of the Freddie Gray incident may be a case in point, since its commissioner was fired amid violent protests that erupted following Gray's death. The crisis was averted and legitimacy restored, at least at a level that suffices. In the twenty-first century, there are other options for restoring legitimacy: accepting 
mandated reforms in a consent decree, or asking the COPS Office to undertake the collaborative reform initiative in your department.

Agencies whose legitimacy is not threatened may be able to build up levels of trust beyond that necessary for survival; stockpiling good will is a legitimation strategy (Suchman 1995). A symbolic display may be a way to gain some additional trust, even when an agency has enough to get by without it. So while organizational legitimacy is dichotomous or trichotomous, aggregate public trust is continuous, and public trust can sink to levels at which organizational legitimacy may be threatened.

\section{Challenges to Legitimacy}

Challenges to a police department's legitimacy can surely be mounted most effectively by its sovereigns - say, the city's mayor, the courts, or DOJ litigatorsbut they can also be initiated by a mobilized public. The protests surrounding shootings by police and other deaths while in police custody in 2014 and 2015 illustrate such threats to police legitimacy, and so does the civil unrest and rioting in the 1960s. Protests over police use of deadly force, or other police practices, can be characterized as a challenge or threat to an agency's legitimacy in that they are claims that the department's operations are not "proper, or appropriate within some socially constructed system of norms, values, beliefs, and definitions" (Suchman 1995, 574). Certainly large-scale demonstrations, and those that are repeated over days or weeks, attract attention to a set of grievances and mobilize support for addressing those grievances. While they may not jeopardize the survival of a police organization, they may be able to generate pressure that is sufficient to prompt organizational change, at least change of a symbolic nature. But in order to do so, the support of sovereigns for change must at some point be enlisted.

It would be easy-but mistaken - to see the riots that rocked Ferguson, Missouri, Baltimore, and other cities in 2014-15 as reflections of the depth of distrust of police, just as it would have been a mistake to interpret the 1967 riots in Detroit, Newark, and elsewhere as a products only of grievances against the police. The Kerner Commission surmised that the riots of 1967 were rooted in a number of intersecting conditions:

- Pervasive discrimination and segregation in employment, education, and housing, which have resulted in the continuing exclusion of great numbers of Negroes from the benefits of economic progress;

- Black in-migration and white exodus, which have produced the massive and growing concentrations of impoverished Negroes in our major cities, creating a growing crisis of deteriorating facilities and services and unmet human needs;

- The black ghettos, where segregation and poverty converge on the young to destroy opportunity and enforce failure. Crime, drug addiction, dependency 
on welfare, and bitterness and resentment against society in general and white society in particular are the result.

Police practices were among the grievances held at the highest level of intensity, along with unemployment and inadequate housing, but inadequate education, poor recreational opportunities, and others were enumerated by the commission. Commentary on the 2014 rioting in Ferguson offered similar diagnoses (Sneed 2014).

Academic research on race riots has confirmed that the conditions that underlie such violent protest extend well beyond police practices, even as policing may contribute to those conditions, and an incident involving the police may be the final (if not the only) precipitating event. Empirical support has been found for the role of social marginality or disadvantage in racial violence, and also for the impact of "closed and unresponsive political systems" that provide no channels through which grievances can be addressed (Lieske 1978, 1329). Other research has pointed toward "hypersegregation of Blacks in urban settings" that breaks down, with increasing interracial contact and competition (Olzak et al. 1996).

Insofar as police practices comprise a patch in a much larger quilt of social, economic, and political conditions that give rise to racial unrest, reforming police practices is by itself no solution. Confronted by a galaxy of problems that are in many ways intractable, local and even state and national sovereigns might be expected to direct attention to police reform as a feasible response. Those reforms need not, however, be compatible with the technical demands of police work or with other existing organizational structures.

\section{TRUST AND OBLIGATION IN SCHENECTADY AND}

\section{SYRACUSE}

Previous research has identified several categories of outlooks that may relate to the social psychological construct of legitimacy, and which may be strongly intercorrelated: trust; confidence; and identification. In addition, these attitudes are thought to be strongly associated with citizens' support for police, belief in empowering police, and citizens' sense of obligation to obey. Both the police services survey and the key informant survey included items on trust, identification, and empowerment, and the police services survey also included items on obligation. We summarize our analyses of these survey responses here, and we also construct indices of trust and obligation based on the police services survey data for analysis in a later chapter. ${ }^{6}$ We reserve an examination of survey results over time until chapter 8 . First, however, we describe the police services and key informant surveys; some readers may wish to skip over this treatment of research methods and go directly to the findings in the section on trust and confidence. 


\section{Survey Methodologies \\ The Police Services Survey}

The police services survey was designed primarily to capture citizens' subjective experience with police, that is, the quality of police service from citizens' perspectives, but it also extended to citizens' more general judgments about and attitudes toward the police. We sampled police records of various kinds to represent, as much as possible, the entire population of police contacts with citizens. Thus the design provided for sampling records of calls for service, stops, and arrests. After a pilot test of the survey in July 2011, we commenced it on August 1, beginning with samples of incidents that occurred in the latter half of July (July 16-31). We continued to draw new samples semi-monthly over thirtysix waves of surveying, or eighteen months. We treated the first 7-10 waves as a baseline, and thereupon began providing monthly summaries of the previous month's performance to each department's command staff in the context of the department's Compstat meeting. The survey also served as an outcome measure, of course, as one month's performance measures were the previous month's outcomes.

Three Types of Contacts. Half or more police-citizen contacts in cities arise from calls for service (Parks et al. 1999; also see Eith and Durose 2011). They are in important respects voluntary contacts, initiated by citizens, who request some form of assistance. ${ }^{7}$ The nature of the problems or issues about which citizens seek assistance is quite heterogeneous, however, and the assistance that citizens request takes many different forms; sometimes citizens want or demand services that police cannot provide. But citizens who dial 911 or other police numbers bear as close a resemblance to "customers" as any with whom police deal.

Traffic stops, and other field stops, have been and continue to be the subject of much controversy. Police claim that high levels of such police proactivity have crime-control benefits, and research tends to bear those claims out (Boydstun 1975; Sampson and Cohen 1988; Whitaker et al. 1985; Wilson and Boland 1978; also see Cohen and Ludwig 2003; McGarrell et al. 2001; Sherman and Rogan 1995; Rosenfeld et al. 2014). But critics point to frequent violations of constitutional limits on police authority, and racially disparate impacts, as reasons to more closely regulate police-initiated contacts. Stops are also a heterogeneous category of events, including routine stops of traffic law violators, pretext stops of traffic law violators motivated by crime-control objectives, and investigatory stops of pedestrians, which are often based only on reasonable suspicion. Stops are not, of course, sought by citizens, and they are thus thought to raise more doubts among citizens about the propriety of police intervention (Reiss 1971).

Both calls for service and stops are defined by how they begin. Either type of contact may end in a variety of ways. Calls for service can prompt a wide range 
of police responses, at the discretion of officers, varying simultaneously along dimensions of control and support. The dispositions may or may not accord with citizen preferences, and they may or may not resolve the situations satisfactorily. Citizens may or may not consider the outcomes favorable. Stops also can involve any of a variety of police actions and eventuate in any of a variety of dispositions, though arguably a narrower range of dispositions than calls for service. Traffic law violators may be lectured, admonished, and/or ticketed. Motorists' vehicles may be searched, with or without the consent of the motorist. Warrant checks may be conducted. Questions may be asked, citizens frisked. Most stops that do not culminate in a ticket will end with the citizen being released in the field. Some, however, will be arrested and taken into custody.

Arrests might stem from either calls for service or stops. They are a type of contact defined by how the contact ends rather than how it begins. The outcome for the citizen is unambiguously unfavorable, and unfavorable to a degree that far exceeds that of a ticket; the citizen is often booked and at least briefly incarcerated, and may be held pending arraignment. The arrest could be based on another citizen's complaint, on an officer's own observations, or both. Many arrests, as Egon Bittner (1974) surmised, are made in order merely to handle the situation, and not primarily because the law has been violated. Arrestees are people who, for whatever reason, did not benefit from the tendency of the police to underenforce the law (Wilson 1968), which is often a discretionary choice. Previous research, with very few exceptions, has not examined the judgments of arrestees about their treatment by police.

The sample of contacts in each site represented all of these contacts, but we oversampled those in which procedural justice is presumptively more challenging: stops and arrests. In this way we were more likely to achieve subsamples of a size that would support separate analysis. Results were weighted as necessary in order to represent the entire population of contacts (i.e., calls were weighted more heavily for such analysis).

Survey Content. We formed a survey instrument based on previously fielded surveys, such that all of the items had been pretested, in effect, and many of the items have a lineage that includes many surveys over decades. Some items, for example, were drawn from the surveys that Wesley Skogan administered in Chicago in the 1990s, and they had also been used in surveys by the Police Foundation in the 1980s. Many other items, tapping elements of procedural justice or legitimacy, were drawn from survey research conducted by Tom Tyler and others. Still other items were drawn from the Police-Public Contact Survey (PPCS), developed and administered by the Bureau of Justice Statistics in the 1990s. Respondents were informed that their names had been drawn from police records, and that we were interested in their contact with the police on a 
specified date, but were not told that we had information on the nature of that contact. Like the PPCS, our survey instrument allowed respondents to tell us how their encounter with police began, with a series of questions tailored to the nature of the contact: a motor vehicle stop; a pedestrian stop; a call to report a crime; a call for some other kind of assistance; or being contacted by police in some other way (e.g., when someone else calls police). The instrument also allowed respondents to self-report arrests. ${ }^{8}$ Most of the interview concerned the sampled contact, but prior to that series of questions, respondents were asked a set of items about the legitimacy of their city's police more generally. Some items were unique to particular types of contacts, for example, only those who had called for assistance or to report a crime were asked whether the police had solved the citizen's problem, and queries about experiences with searches were posed only to those who were stopped by police. Demographic information was also collected.

Samples. Our design provided for sampling contacts from police records of calls for service, stops, and arrests in each department, and conducting interviews by phone with the citizens named in those records. Samples were drawn semimonthly from records of contacts that occurred between July 15, 2011, and January 15, 2013. Calls for service records were extracted from each department's computer-aided dispatch (CAD) system. Arrest records were extracted from each department's record management system, and included custodial arrests as well as cases in which suspected offenders were either issued appearance tickets or released on their own recognizance. Records of stops differed across the departments: Syracuse has for many years provided for a citizen contact form on which officers record all stops that do not result in arrest; these records include stops in which a traffic ticket is issued. Schenectady, however, does not have a comparable record of stops, but rather separate records of traffic tickets and "field interview cards." Field interview cards may be completed pursuant to any contact with a citizen, whether it is police-initiated or not, but most field interview cards are based on police-initiated contacts. In Schenectady we sampled only field interview cards, since sampling traffic tickets was not at that time feasible. Thus the samples of stops in the two cities are different, in that routine traffic stops are included only in Syracuse.

In general, the interviewed sample resembles the eligible population in each site fairly closely (details are provided in the methodological appendix). Since the samples are stratified, with different probabilities of sample selection across the different subpopulations, and since the response rates varied across subpopulations, we weight the cases for most analyses of the survey data in order to represent the entire contact population in each site. We apply weights that reproduce the original population proportion that each subpopulation represents, though these 
weights are very nearly the same as those that are based only on the probabilities of sample selection (with correlations over 0.90).

\section{Key Informant Survey}

We administered a three-wave key informant panel survey with two objectives: to provide a description of the legitimacy that community members attribute to the study police departments, and then to compare responses over time to assess whether departments' efforts to cultivate improved police-citizen relations by actively assessing satisfaction had an impact on the public's views about police legitimacy. While the police services survey included items about police legitimacy, it was limited to people who had contact with the police, and the key informant survey complements the police services survey by providing information on the perspectives of the community more generally.

In general, key informants are persons whose organizational roles imply they have special knowledge about the population being studied. For our purposes, we operationalized key informants as current leaders of a neighborhood association in Schenectady or Syracuse. To identify neighborhood associations and their respective leaders in each city, we relied on contact lists provided to us by representatives of the police departments. Both police departments maintain up-to-date lists of associations and contact information for leaders, which include, in many cases, email addresses.

In Wave 1, surveys were distributed to key informants by a private e-mail weblink and paper copies were mailed, with a prepaid postage return envelope, to respondents for whom we had no e-mail address. We asked respondents in Wave 1 for whom we had no e-mail address to provide us with one for follow-up surveying; all respondents complied. Therefore, in subsequent waves we relied exclusively on the e-mailed weblink.

Nine in ten of Syracuse informants had lived in the city for six or more years (75 percent for eleven or more), and the majority (83.4 percent) had lived in their current neighborhood for six years or more. All Syracuse respondents reported they had been active members of their neighborhood association for more than one year, with the greatest proportion (45 percent) reporting three to five years of active involvement, and one-third reporting involvement for six or more years. The majority (68.2 percent) reported holding a leadership position for three years or more.

Consistent with Syracuse, nine in ten Schenectady informants (92.8 percent) reported that they had lived in the City for six years or more, and the majority (85.7 percent) had lived in their current neighborhood for six or more years. All Schenectady respondents reported being active in their neighborhood association for more than a year with the majority (64.2) reporting six or more years of active membership, with the greatest proportion (57.1 percent) reporting eleven or more years of active membership. 


\section{Trust and Confidence}

Legitimate authorities can be trusted to do the right thing, and to make proper decisions. The surveys provide for several measures of trust and confidence in the form of statements with which survey respondents could agree or disagree:

- I have confidence that the S PD can do its job well.

- I trust the leaders of the SPD to make decisions that are good for everyone in the city.

- The police can be trusted to make decisions that are right for the people in my neighborhood.

- There are many things about the SPD and its policies that need to be changed.

In general, two-thirds to three-quarters of the people with whom police had contact during the eighteen months of the survey expressed trust and confidence in the police, though the proportions were somewhat higher in Syracuseparticularly the proportions expressing strongly favorable views. By comparison, the proportions of key informants expressing trust in the police were somewhat higher in Syracuse and lower in Schenectady, but the samples are small and not too much should be made of the differences across the surveys. But among both sets of respondents, the Syracuse police appear to enjoy a more favorable public image, which is consistent with the recent histories of the departments and hence consistent with our expectations. The exception to the generality about trust lies in citizens' assessments of the need for change: 62 to 69 percent of the police services survey respondents in both sites said that there were "many things" about the police department and its policies that needed to be changed, with still higher proportions among key informants.

\section{Identification}

People identify with and feel connected to authorities that they consider legitimate, and from their association with legitimate authorities people derive a measure of status (see Tyler and Fagan 2008). Identification is measured through statements with which respondents could agree or disagree:

- I am proud of the work of the S___ police.

- You can usually understand why the police who work in my neighborhood are acting as they are in a particular situation.

- If you talked to most of the police officers who work in my neighborhood, you would find that they have similar views to my own on many issues (police services survey only).

- Most of the police officers who work in my neighborhood have similar views to my own on many issues (key informant survey only). 
With responses that were largely congruent with those on the trust items, 62 to 75 percent of the people with whom police had contact identified at least somewhat with the police, with similar to somewhat larger proportions among key informants.

\section{Empowerment}

People are willing to grant a lot of latitude to authorities they consider legitimate, thereby empowering the authority (Sunshine and Tyler 2003). We measure empowerment with these survey items:

- The police should have the right to stop and question people on the street.

- There need to be clear limits on what the police are allowed to do in fighting crime (police services survey only).

- The police should have the power to do whatever they think is needed to fight crime (police services survey only).

- Leaders of the SPD believe that police should work with citizens to try to solve problems (key informant survey only).

People appear to be somewhat conflicted, as more than 80 percent espouse the need for clear limits on crime-fighting by police, while more than half say that police should have wide latitude in fighting crime.

Key informants were also asked for their views on a few other items:

- The SPD take a tough stance on improper police behavior.

- The SPD has effective procedures for preventing improper police behavior.

- Leaders of the SPD believe that the police should be accountable to the communities they serve.

- The SPD considers community satisfaction an organizational priority.

Responses to these statements also reflected perceptions that were predominantly favorable to the police, expressing faith in the orientation of the police and police leadership toward the community, and in its commitment to police rectitude. Half to two-thirds of key informants agreed with these statements. But insofar as the responses differ across the cities, the differences on these items are in favor of Schenectady police.

\section{Obligation}

Obligation is the belief that an authority should be obeyed; the greater the legitimacy, the greater the obligation to obey. Police services survey respondents were asked to agree or disagree with these statements:

- Communities work best when people follow the directives of the police.

- There are times when it is okay to ignore what the police tell you to do. 
- You should do what the police tell you to do even when you don't like the way they treat you.

- You should accept the decisions made by police even if you think they are wrong.

Generally, three-quarters or more of the people who had a police contact believed that people should obey police commands. About two-thirds believed that such obedience was called for even when police do not treat them properly. Nearly half believe that people should obey police even when they think that police are wrong. Patterns of responses were very similar across the two sites.

\section{Attitudinal Dimensions}

As we discussed earlier in this chapter, previous social psychological research on legitimacy exhibits no clear consensus on the measurement of legitimacy or its presumed component dimensions, but it appears prudent for both theoretical and empirical reasons to treat obligation as a distinct construct, separate from trust and confidence in police. In their analysis of the construct validity of processbased measures, Michael Reisig et al. (2007) concluded that trust and obligation are distinct constructs only moderately related to one another, and Jacinta Gau's (2011) findings led to the same conclusion.

Our analysis of the fourteen items posed on the police services survey and summarized above suggests that the trust and identification items reflect a single attitudinal dimension, which we will simply call trust. (In this respect our findings are consistent with those of Tyler and Fagan 2008.) Factor analyses of the fourteen items and of subsets thereof repeatedly yield a factor on which the seven trust and identification items load strongly, and the average inter-item correlation among these seven items is $0.51 .{ }^{9}$ The obligation items also formed a distinct dimension, as in previous research. The empowerment items, however, loaded on a separate factor, and these items do not comprise a reliable scale, with an average inter-item correlation of only 0.25 . Thus we formed two indices, one of trust and the other of obligation.

The trust index is a simple additive scale based on the seven trust and identification items, each of which was centered at zero (don't know responses and refusals) and provided two values above and below zero for strong and moderate (dis)agreement, respectively (and reverse coded as necessary). This additive index is virtually identical statistically to the factor scale that is formed by weighting the items in proportion with the factor coefficients. The trust index ranges potentially from -14 to 14, with an alpha of 0.88 . The distribution of cases across categories of trust for each site is shown in Figure 2, along with the means for each subpopulation.

If we translate the trust index into a 4-point scale resembling those formed in previous research (with high distrust assigned a 1 and high trust assigned a 4), the means of 2.8 and 3.0 (in Schenectady and Syracuse, respectively) are similar to the 


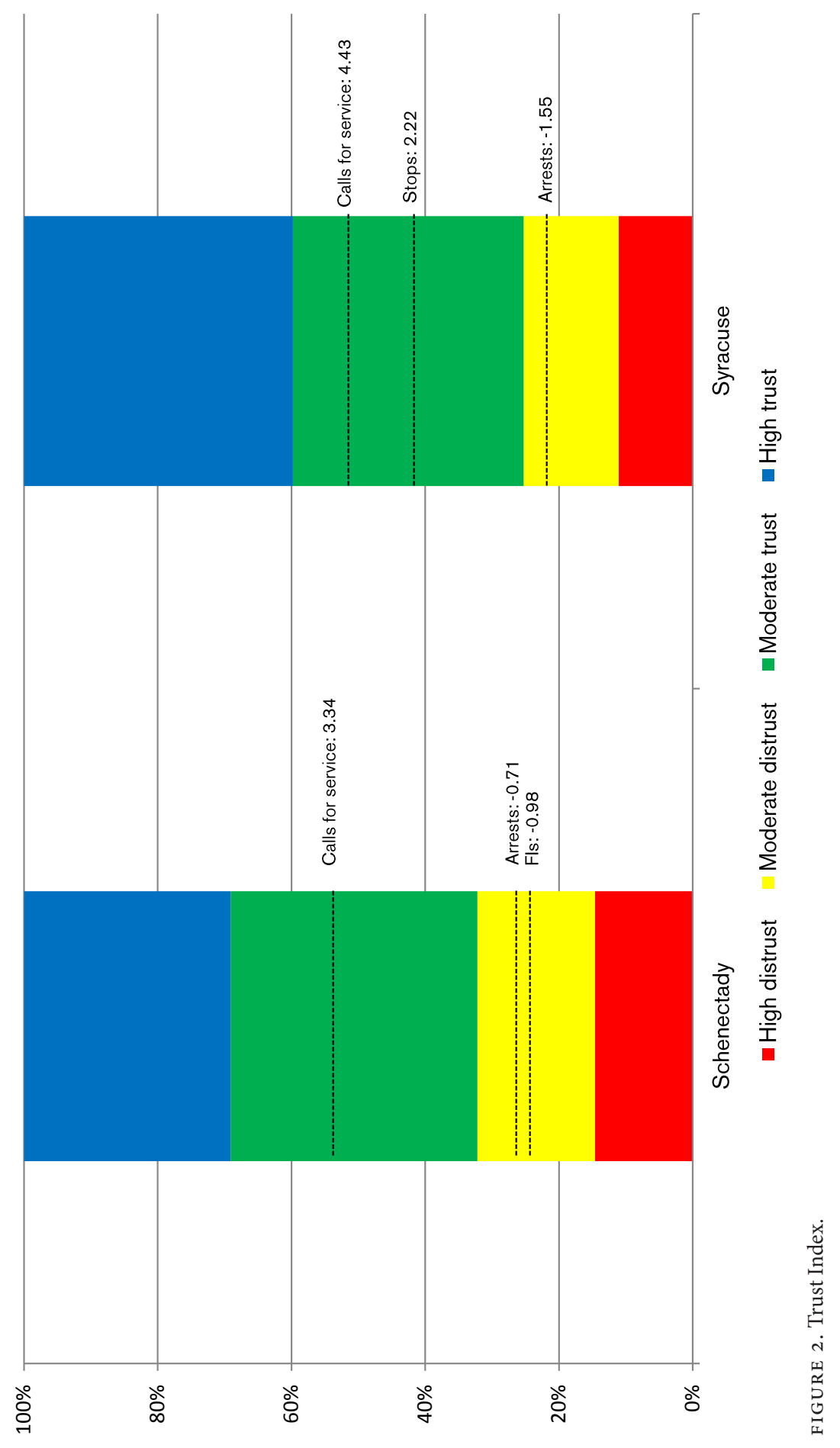


levels of legitimacy reported by Tyler (2005) and Tyler et al. (2010). Inflated (by 25 percent) to render the index comparable to five-point scales formed in previous research, the means of 3.5 and 3.8 are similar to the levels of legitimacy reported by Tyler and Fagan (2008), Murphy and Cherney (2012), and Murphy et al. (2008).

The obligation index is also an additive scale, based on three (of the four) obligation items, each of which was centered at zero (and reverse coded as needed). ${ }^{10}$ The obligation index ranges from - 6 to 6, with an alpha of 0.64 . The distribution for each site, and the mean for each subpopulation, is shown in figure 3. Overall, the means are 1.77 and 1.67 for Schenectady and Syracuse, respectively. The obligation index scores are not different across the sites, on average.

The disparity in the public images of the departments, which we described in chapter 2, is not clearly detectable in the distributions and central tendencies of the trust index in the two sites. The mean scores are different-higher in Syracuse than in Schenectady-and the difference is statistically significant. Three-quarters of the Syracuse respondents, compared with about two-thirds of the Schenectady respondents, have index scores in the higher ranges of values. But the difference is not wide, especially in view of the circumstances that detracted from the legitimacy of the Schenectady police. Two-thirds of the people who had contact with the Schenectady police expressed, on balance, trust rather than distrust. Two-thirds or more of the key informants in Schenectady likewise expressed trust in the department and its leaders.

The expected difference in trust levels across the two cities is further contradicted by a comparison of trust levels in individual contact populations, which are not all of the same magnitude or even direction: among people who called for service, trust is higher in Syracuse, but among people who were arrested, trust is lower in Syracuse. The sample of people who were stopped in Syracuse exhibit higher levels of trust, but the two samples are not directly comparable, since the stops in Schenectady do not represent as well as those in Syracuse the people subject to routine traffic stops.

Thus we do not see in these data on public trust and confidence a clear indication of the crisis of legitimacy that Schenectady police suffered. Sovereigns in Schenectady could plainly see in the misadventures of individual officers symptoms of mismanagement, which (we infer) led them to challenge the department's legitimacy. The judgments of the broader public, however, were seemingly less affected by the unflattering reports of officers' misconduct. Compared with the judgments of those who encountered the Syracuse police, the legitimacy of which was not at issue, the judgments of those who encountered the Schenectady police were only slightly less positive. We lack data on public trust and confidence over time, and so we cannot establish that public attitudes were stable. But these findings are consistent with the proposition that a police department's legitimacy turns principally on the judgments of sovereigns such as legislators, elected executives, 


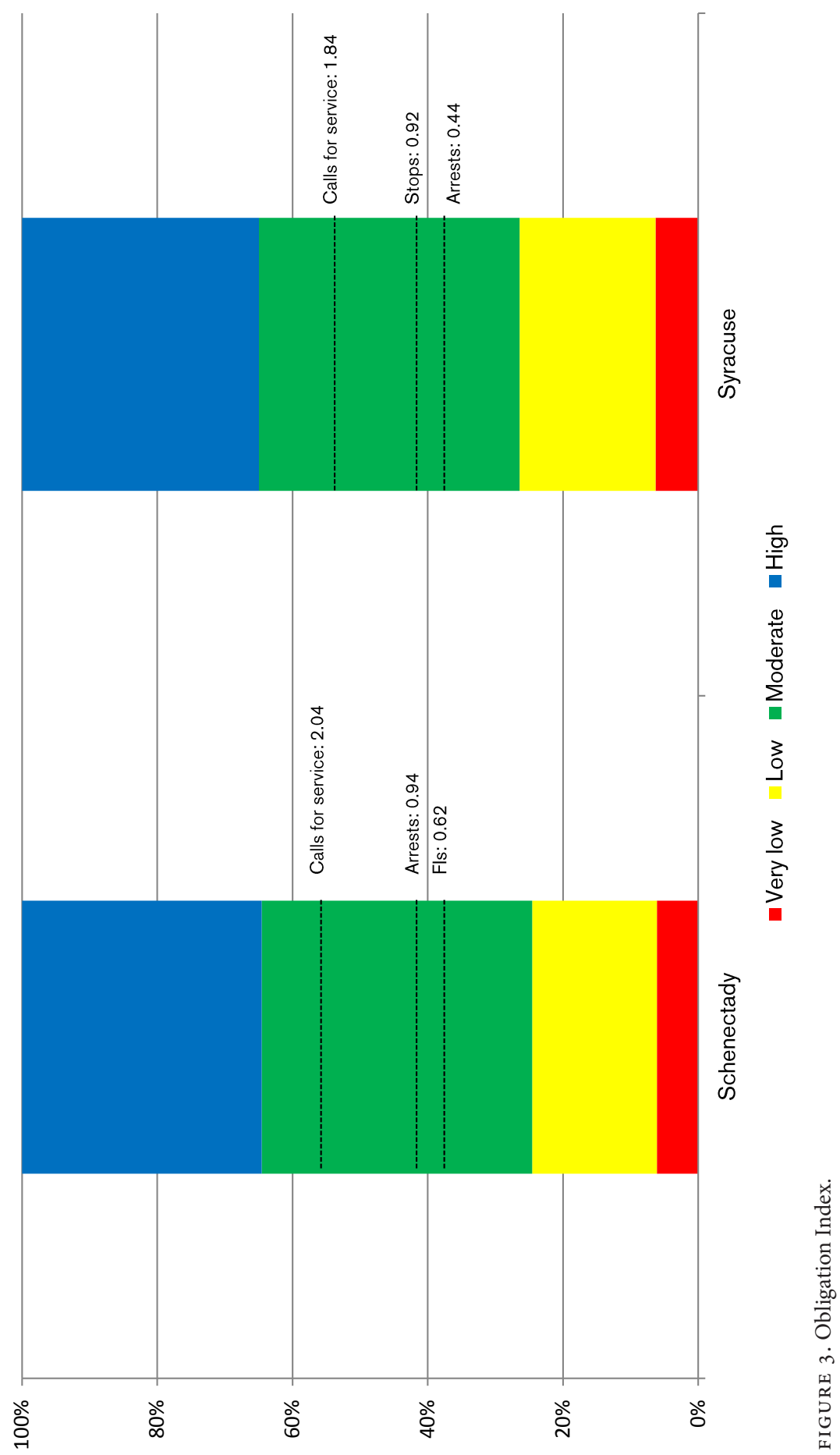


courts, and other parties - such as the Civil Rights Division of the Department of Justice-to make or influence authoritative decisions about the organization.

\section{SUMMARY}

We briefly reviewed extant research on police legitimacy and, more generally, citizens' attitudes toward the police. Previous research findings testify to the myriad influences on citizens' outlooks, which are subject to long-term forces (e.g., postmaterial values) and to factors that are more narrowly circumscribed temporally and spatially, such as the perceived level of social and physical disorder in one's neighborhood and the reputation of the local police (for good or ill), but among which the performance of the police in police-citizen encounters is but one. Citizens' attitudes are rather tenuously connected to their direct, personal experiences with the police.

Using survey items identical to those used in previous survey research, we find in Schenectady and Syracuse patterns of trust and obligation that resemble those reported in previous research. First, citizens overall reported fairly high levels of trust and confidence in their police departments, with two-thirds to three-quarters in agreement with statements that police can be trusted to make good decisions, that they have confidence in the police, and that they are proud of their police. Second, seven survey items were strongly intercorrelated and form a scale of trust and confidence that is reliable. As in previous research, obligation forms a distinct construct, and while it is related to trust, the obligation items appear to tap a separate attitudinal dimension. Finally, the two sources of data on citizens' perceptions were only weakly consistent with our initial supposition that Syracuse police enjoyed greater public trust and confidence at the project's outset, and the differences were not nearly so stark as might have been expected, given Schenectady's crisis of legitimacy in the decade preceding our surveying. Public trust, it appears, was less susceptible to the reported misdeeds of Schenectady police than were the judgments of sovereigns, suggesting that organizational legitimacy turns more on the latter than the former. 